\title{
Enhancement of cold hardiness by acclimation is stage-specific in the non-diapausing pupae of onion maggot Delia antiqua (Diptera: Anthomyiidae)
}

\author{
Shoichiro MIYAZAKI, TAKumi KAYUKAWA, Bin CHEN, MichiKazu NOMURA and Yukio ISHIKAWA* \\ Laboratory of Applied Entomology, Graduate School of Agricultural and Life Sciences, The University of Tokyo, \\ Tokyo 113-8657, Japan
}

Key words. Diptera, Anthomyiidae, Delia antiqua, cold hardiness, cold acclimation, supercooling point, trehalose, head evagination, phanerocephalic pupa, pupariation

\begin{abstract}
When puparia of the onion maggot Delia antiqua were preexposed to $5^{\circ} \mathrm{C}$ for 5 days starting at different time points after pupariation, a large increase in survival after exposure to $-20^{\circ} \mathrm{C}$ for 5 days was observed only when pre-exposure was initiated at 3-6 days after pupariation. The increase in cold hardiness was not associated with a large increase in the trehalose content of the puparia. The supercooling point of the puparia naturally decreased from -18 to $-27^{\circ} \mathrm{C}$ in the first three days after pupariation, and pre-exposure to $5^{\circ} \mathrm{C}$ did not have an additional effect. Thus, factors responsible for the enhancement of cold hardiness by acclimation other than trehalose and supercooling point should be sought. The period of responsiveness to cold acclimation coincided with the time soon after head evagination, which corresponds to "pupation" in lepidopteran insects. The puparia appear to be physiologically flexible for a short time after head evagination, and able to adapt their physiology to the contemporary cold environment.
\end{abstract}

\section{INTRODUCTION}

The onion maggot Delia antiqua (Diptera: Anthomyiidae) shows extensive cold hardiness in the pupal stage (Nomura \& Ishikawa, 2001). Even non-diapausing pupae can survive storage at $4{ }^{\circ} \mathrm{C}$ for a long period. Most of the pupae survive up to six months of storage when the puparia are transferred to $4^{\circ} \mathrm{C}$ at three to five days after pupariation. We are interested in the strong cold-hardiness of non-diapausing $D$. antiqua pupae and have conducted various preliminary experiments to find clues to the mechanisms of cold-hardiness in this species. These studies have shown that pre-exposure of puparia to a temperature slightly lower than developmental zero $\left(5.7^{\circ} \mathrm{C}\right)$ for a short period (cold acclimation) greatly enhances survival at subzero temperatures (e.g. $\left.-20^{\circ} \mathrm{C}\right)$.

In the present study, we quantitatively evaluated the effect of acclimation on cold hardiness and examined whether there is a specific period in the life of puparia responsive to the acclimation. In parallel, the changes in supercooling point (SCP) and trehalose content of the puparia were monitored because lowering the SCP is an important strategy to cope with cold for freeze intolerant insects like $D$. antiqua (see Lee \& Denlinger, 1991), and trehalose is the principal cryoprotectant in this species (Nomura \& Ishikawa, 2001) as well as in a congener $D$. radicum (Koštál \& Šimek, 1995).

\section{MATERIAL AND METHODS}

Insects

The onion maggot used in experiments originated from a population collected at the Hokkaido National Agricultural Experiment Station, Sapporo, Japan. Flies were housed in screen cages with a supply of water, cube sugar and yeast extract, and maintained at $23 \pm 1{ }^{\circ} \mathrm{C}$ under a photocycle of $16 \mathrm{~L}: 8 \mathrm{D}$. Eggs were inoculated on a piece of artificial diet (Ishikawa et al., 1983) placed on moistened fine sand in a plastic container and maintained in an incubator $\left(20 \pm 0.2^{\circ} \mathrm{C}, 16 \mathrm{~L}: 8 \mathrm{D}\right)$. The puparia used for the experiments were collected daily 17-21 days after inoculation. After tap water was poured into the rearing container and stirred gently, the larvae and puparia were decanted onto a sieve and only puparia colored white or pale-orange, which indicates that the puparia were formed within one hour, were collected (day-0 puparia).

\section{Cold treatment of puparia}

Staged puparia were placed on a sheet of wet filter paper in a Petri dish $(6 \mathrm{~cm}$ in diam.) and the dish was sealed with MilliWrap ${ }^{\circledR}$ tape. The control puparia were maintained at $17.0 \pm$ $0.2^{\circ} \mathrm{C}$ and $16 \mathrm{~L}: 8 \mathrm{D}$ throughout. Under these conditions head evagination occurred at the end of day $2(65.5 \mathrm{~h}$ after pupariation; the day of pupariation being day 0 ). The puparia for cold treatment were divided into two groups. In one group, the puparia were maintained at $17.0^{\circ} \mathrm{C}$ for $1,2,3,4,5,6,7$ or 10 days, and then immediately subjected to $-20 \pm 0.2^{\circ} \mathrm{C}$ treatment for 5 days. In the other group, the puparia were pre-exposed to $5.0 \pm 0.2^{\circ} \mathrm{C}$ for 5 days prior to the $-20^{\circ} \mathrm{C}$ treatment. Since $5.0^{\circ} \mathrm{C}$ is below the lower threshold for puparial development $\left(5.7^{\circ} \mathrm{C}\right)$ it was assumed that no development occurred during the preexposure. For treatment at $-20^{\circ} \mathrm{C}$, wet filter paper in the Petri dish was replaced with dry filter paper and the puparia were dried at $17^{\circ} \mathrm{C}$ to prevent inoculative freezing. After the $-20^{\circ} \mathrm{C}$ treatment, the puparia in both groups were maintained at $17.0^{\circ} \mathrm{C}$ for 30 days to allow the flies to emerge. After this period, the puparia were dissected to examine their state. Dead insects could be easily distinguished by their desiccated and shrunk bodies.

\section{Measurement of supercooling point (SCP)}

In order to avoid inoculative freezing, the surface of the puparium was dried by placing it on filter paper for $1 \mathrm{~h}$. Each puparium was then attached to the tip of a copper-constantan thermocouple with a minimum amount of Vaseline. The puparia attached at the tip of sensors were hung in a glass tube $(4 \mathrm{~cm}$ diam. $\times 10 \mathrm{~cm})$. The tube was immersed in an ethyl alcohol bath and the bath temperature was lowered at a rate of -0.5 to $-0.6^{\circ} \mathrm{C} / \mathrm{min}$. The temperature at which an abrupt increase

\footnotetext{
* Corresponding author; e-mail: ayucky@mail.ecc.u-tokyo.ac.jp
} 

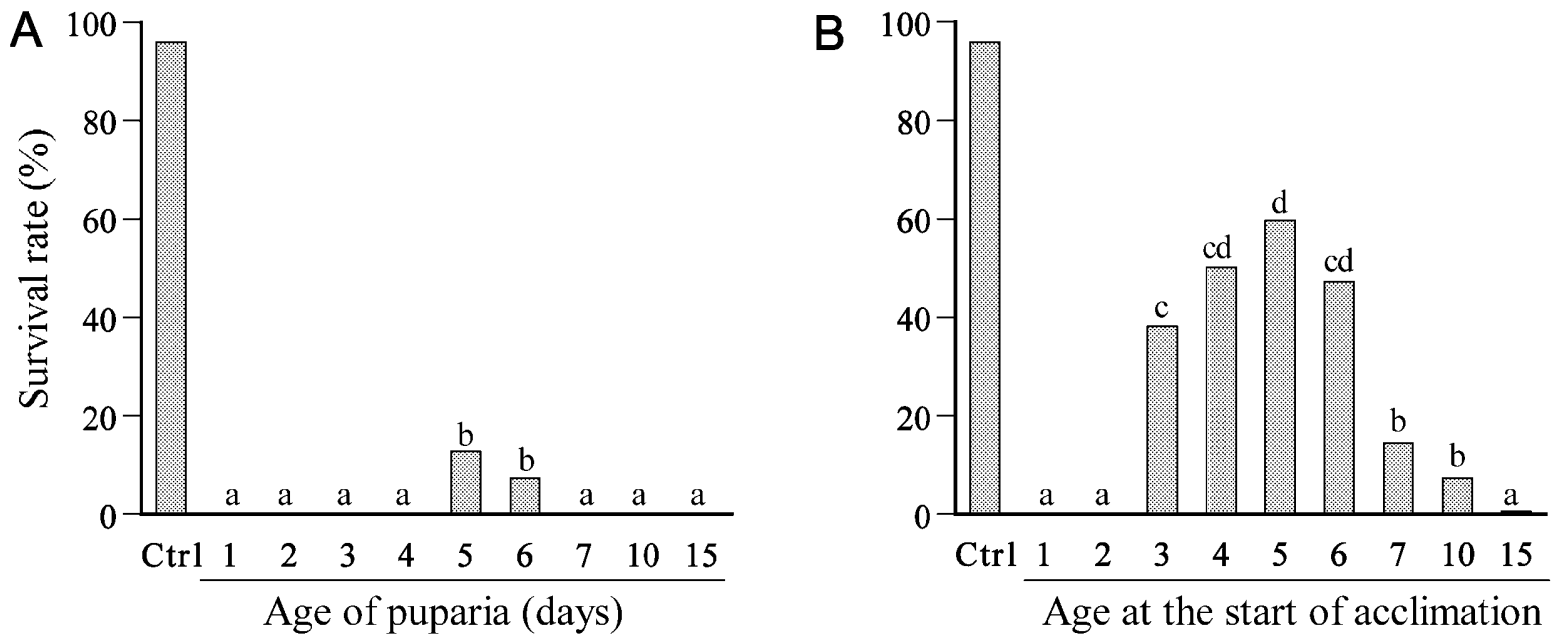

Fig. 1. A - Effect of the age of non-diapausing Delia antiqua pupae on survival after exposure to $-20^{\circ} \mathrm{C}$ for 5 days. B - Effects of the age at the start of acclimation at $5.0^{\circ} \mathrm{C}$ for 5 days on survival after treatment at $-20^{\circ} \mathrm{C}$. Bars with the same letter are not significantly different (Ryan's test on proportions, $\mathrm{P}>0.05 ; \mathrm{n}=200$ ). Controls were maintained at $17^{\circ} \mathrm{C}$.

occurred with the liberation of latent heat on freezing was taken as the SCP.

\section{Body weight and water content}

Body weight

The daily changes in the body weight of puparia were recorded. Each puparium, just after pupariation, was put into a $1.5-\mathrm{ml}$ micro-centrifuge tube and the tube was placed in a Styrofoam box with the cap opened. Since the puparia were susceptible to desiccation just after pupariation, a damp cotton wool pad was placed in the Styrofoam box to keep the humidity at more than $95 \%$. The Styrofoam box was placed in an incubator adjusted to $17.0 \pm 0.2^{\circ} \mathrm{C}$ and $16 \mathrm{~L}: 8 \mathrm{D}$. The puparia were weighed at the same time per day until the emergence of flies (n $=10$ ), with accuracy to within $0.1 \mathrm{mg}$. The change in body weight of the dead puparia, which were killed by exposing them to ethyl acetate vapor for $1 \mathrm{~h}$, was also examined.

Water content of pupae

The puparia were dried at $120^{\circ} \mathrm{C}$ for $24 \mathrm{~h}$ in a forced convection oven. The puparia were weighed to within $0.1 \mathrm{mg}$ before and after drying and the water content (\%) was calculated. The puparia used for the experiment were maintained at $17^{\circ} \mathrm{C}$ and $16 \mathrm{~L}: 8 \mathrm{D}$, and measured on days $0-7$ and $10(\mathrm{n}=10)$.

\section{Measurement of trehalose content}

The samples for the measurement of trehalose were prepared according to Nomura \& Ishikawa (2001). Trehalose in the sample was first converted to glucose by trehalase, and the amount of glucose produced was determined by the glucose oxidase method using a Glucose-B test kit ${ }^{\mathrm{TM}}$ (Wako Pure Chemicals, Osaka),

\section{RESULTS}

\section{Enhancement of cold hardiness}

When $D$. antiqua puparia of different ages were subjected to $-20^{\circ} \mathrm{C}$ treatment without cold acclimation, none survived except for a small proportion (8-13\%) of 5-day-old and 6-day-old puparia (Fig. 1A). A remarkable increase in survival after exposure to $-20^{\circ} \mathrm{C}$ was observed when pre-exposure to $5^{\circ} \mathrm{C}$ was initiated at 3-6 days after pupariation (Fig. 1B). In contrast, no

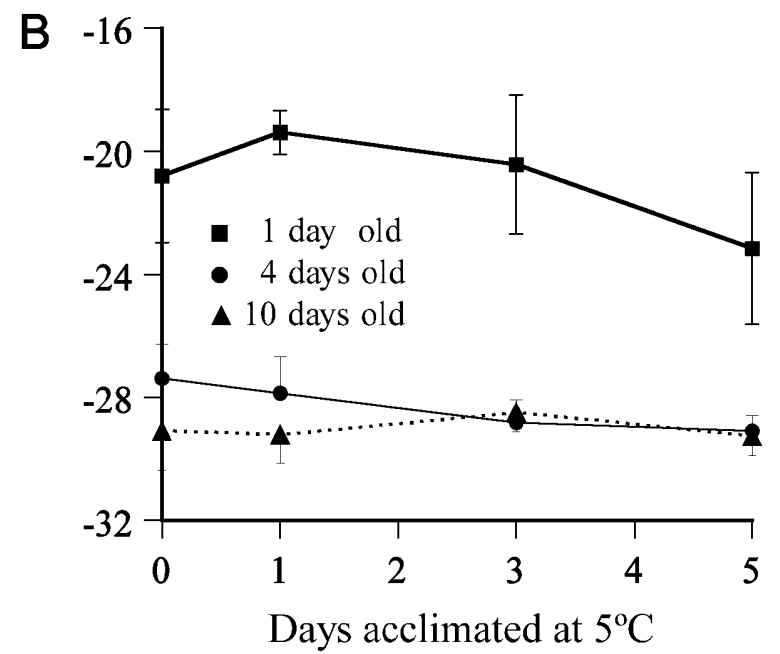

Fig. 2. A - Temporal changes in the supercooling point (SCP) of non-diapausing D. antiqua pupae maintained at $17^{\circ} \mathrm{C}$ and $16 \mathrm{~L}$ : $8 \mathrm{D}($ mean $\pm \mathrm{SD}, \mathrm{n}=9$ ). $\mathrm{B}-$ Effect of cold acclimation on the $\mathrm{SCP}$ of non-diapausing pupae (mean $\pm \mathrm{SD}, \mathrm{n}=6$ ). 

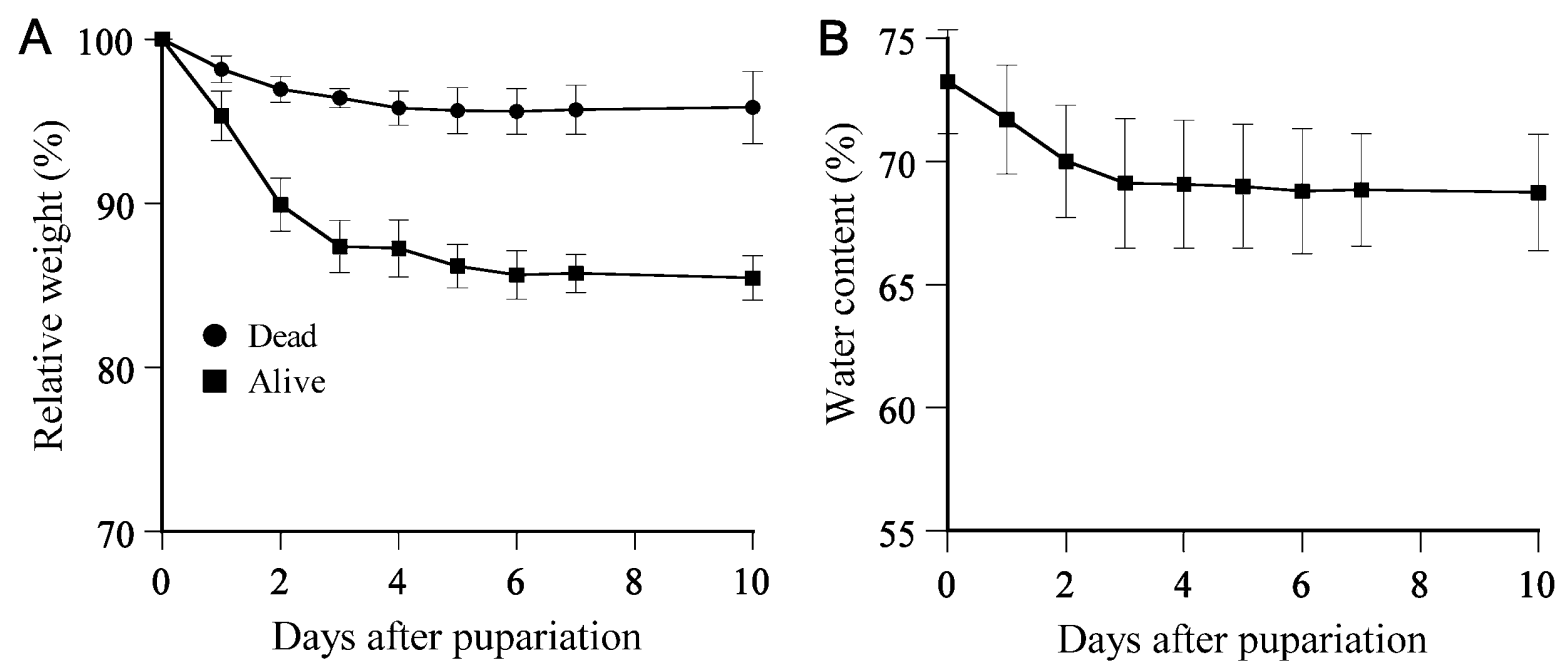

Fig. 3. A - body weight change in living and dead puparia at $17.0^{\circ} \mathrm{C}$ and $16 \mathrm{~L}: 8 \mathrm{D}$ (mean $\pm \mathrm{SD}, \mathrm{n}=10$ ); $\mathrm{B}$ - change in water content of living puparia (mean $\pm \mathrm{SD}, \mathrm{n}=10$ ).

increase in survival after pre-exposure was observed for 1day-old and 2-day-old puparia and a significant but only small increase was observed for 7-day-old and 10-day-old puparia.

\section{Supercooling point (SCP)}

The SCP of puparia decreased sharply from -18 to $-27^{\circ} \mathrm{C}$ in the first three days after pupariation, then fluctuated until day 15 , before increasing sharply to -24 to $-20^{\circ} \mathrm{C}$ (Fig. 2A). The period with the lowest SCP coincided with an apparent arrest of external morphogenesis and the SCP appeared to increase sharply with the restart of morphogenesis. Cold acclimation of 5-day-old puparia, as well as 1-day-old and 10-day-old puparia, had only marginal effects on the SCP (Fig. 2B). It appears that the change in SCP is not involved in the enhancement of cold hardiness caused by the acclimation.

\section{Changes in body weight and water content}

To examine if the initial decrease in the SCP is attributable to dehydration, the body weight and water content of the puparia were measured. The body weight of normal puparia decreased sharply for the first 3 days after pupariation, and thereafter remained at almost the same level throughout the puparial stage (Fig. 3A). The water content of the puparia decreased from $73.2 \%$ to $69.1 \%$ in the first 3 days after pupariation, and this level was maintained throughout the rest of the puparial stage (Fig. 3B). For the puparia killed by ethyl acetate on day 0 (before the completion of cuticular tanning), body weight decreased remarkably more slowly than in the living counterparts (Fig. 3A).

\section{Trehalose content}

The trehalose content of $D$. antiqua puparia on a wet weight basis increased for the first 5 days and thereafter decreased gradually through the rest of development (Fig. 4A). The apparent initial increase in trehalose content is likely to be due to dehydration of puparia during this period (Fig. 3A, B). The trehalose content of both 1-day-old and 4-day-old puparia increased significantly with the cold treatment at $5^{\circ} \mathrm{C}$ (Fig. 4B). However, the increase was very small and not likely to be the major cause of the enhancement of cold hardiness.

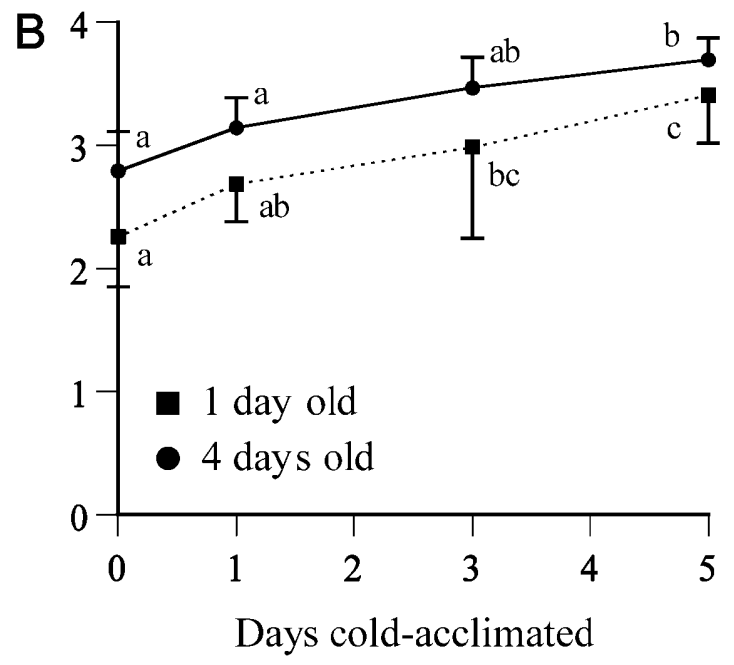

Fig. 4. A - Changes of trehalose content in non-diapausing D. antiqua pupae maintained at $17.0^{\circ} \mathrm{C}$ and $16 \mathrm{~L}: 8 \mathrm{D}(\mathrm{mean} \pm \mathrm{SD}, \mathrm{n}=$ 6). $\mathrm{B}$ - Effect of cold acclimation on trehalose content of non-diapausing pupae (mean $\pm \mathrm{SD}, \mathrm{n}=6)$. Within each series (1-day-old or 4-day-old), symbols with the same letters are not significantly different by the Tukey-Cramer multiple comparison test $(\mathrm{P}>0.05)$. 


\section{DISCUSSION}

\section{Developmental stage responsive to cold acclimation}

A few days after pupariation, "head evagination" occurs within the puparium, which delimits the cryptocephalic and phanerocephalic stages. Developmentally, this head evagination corresponds to the "pupation" in other orders of insects (Fraenkel \& Bhaskaran, 1973). The development of winterdiapausing pupae is known to be arrested shortly after head evagination (Nomura, 2000). The period responsive to cold acclimation coincided with the time soon after head evagination. The puparia appear to be physiologically flexible for a short time after head evagination, and able to adapt their physiology to the contemporary cold environment.

\section{Supercooling point}

The level of SCP right from pupariation $\left(<-18^{\circ} \mathrm{C}\right)$ appears to be low enough to prevent freezing in the temperate regions where D. antiqua distributes. Cold acclimation of 1-day-old puparia for 5 days resulted in a decrease of the SCP by a few degrees (Fig. 2B). Considering that the SCP of puparia naturally decreases to below $-27^{\circ} \mathrm{C}$ by day 3 , the acclimation inhibited this natural decrease. This is probably due to an arrestment of puparial development at low temperature and is consistent with the view that the SCP is actively decreased in association with puparial development. The initial decrease in the SCP may be partly attributed to the active dehydration of the puparia (Fig. $3 \mathrm{~B})$; excretion of osmotically active water is known as an important factor for the decrease of SCP (Danks, 2000). The changes in water content of killed puparia suggest that the dehydration process is energy consuming.

\section{Death of cryptocephalic puparia}

The cryptocephalic puparia appear to have died during or soon after the exposure to $-20^{\circ} \mathrm{C}$, since these puparia became desiccated and shrunk within a few days. Cryptocephalic puparia at 0 and 1 day of age may have died of freezing, because the SCP of puparia at these ages is near $-20^{\circ} \mathrm{C}$ (Fig. 2A). However, 2-day-old and older puparia are not likely to freeze at $-20^{\circ} \mathrm{C}$, since the SCP has fallen substantially below $-20^{\circ} \mathrm{C}$. It is not surprising that cryptocephalic puparia are not very cold hardy, because extensive morphological changes accompanying the histolysis of larval tissues and generation of pupal and adult tissues are in progress (Bainbridge \& Bownes, 1981).

\section{Death of phanerocephalic puparia}

Considering the SCP, the death of the 3- to 15-day-old puparia is not attributable to "freeze injury". Kayukawa \& Ishikawa (2005) have investigated the cause of death of 5-day-old non-diapausing $D$. antiqua pupae (ND5) after $-20^{\circ} \mathrm{C}$ treatment. Analysis of the morphology of dead pupae suggested that they died at two discrete developmental stages: after formation of the adult morphology (type 1), and at a stage indistinguishable from ND5 in appearance (type 2). In the case of type-1 death, pharate adults appeared to have died because they failed to emerge from the puparial case, and the impairment of the neuromuscular system was suggested to underlie this failure. On the other hand, serious damage to the Malpighian tubules was suggested to be the cause of type- 2 death.

\section{Mechanism for enhancement of cold hardiness}

Neither the increase in trehalose content nor decrease in SCP appeared to be the major cause of the enhanced cold hardiness of the acclimated phanerocephalic pupae. D. antiqua pupae enter summer and winter diapauses shortly after the head evagination (Ishikawa et al., 2000; Nomura, 2000). We considered that similar mechanisms underlie the enhanced cold hardiness of diapausing pupae and the cold-acclimated non-diapausing pupae, although the diapause is induced programmatically based on past environmental conditions while the acclimation is a direct response to the current environment. Based on this hypothesis, we have recently analyzed the genes differentially expressed among non-diapausing, cold acclimated nondiapausing, summer diapausing, and winter diapausing pupae (Chen et al., 2005a; Kayukawa et al., 2005). It was shown that expression of the genes for a subunit of chaperonin CCT (t-complex polypeptide-1, tcp-1) (Kayukawa et al., 2005), DaTrypsin (Chen et al., 2005a), and heat shock protein 90 (Chen et al., 2005b) is similarly up-regulated by cold acclimation, and during summer and winter diapauses. Further studies to critically evaluate the contribution of these factors to the enhancement of cold hardiness are required.

\section{REFERENCES}

BAinbridge S.P. \& Bownes M. 1981: Staging the metamorphosis of Drosophila melanogaster. J. Embryol. Exp. Morphol. 66: 57-80.

Chen B., Kayukawa T., Jiang H., Monteiro A., Hoshizaki S. \& IsHIKAWA Y. 2005a: DaTrypsin, a novel clip-domain serine proteinase gene upregulated during winter and summer diapauses of the onion maggot, Delia antiqua. Gene 347: $115-123$.

Chen B., Kayukawa T., Monteiro A. \& Ishikawa Y. 2005b: The expression of HSP90 gene in response to winter and summer diapauses and thermal-stress in the onion maggot, Delia antiqua. Insect Mol. Biol. 14: 697-702.

DANKS H.V. 2000: Dehydration in dormant insects. J. Insect Physiol. 46: 837-852.

Fraenkel G. \& Bhaskaran G. 1973: Pupariation and pupation in cyclorrhaphous flies (Diptera): terminology and interpretation. Ann. Entomol. Soc. Am. 66: 418-422.

Ishikawa Y., Mochizuki A., Ikeshoji T. \& Matsumoto Y. 1983: Massrearing of the onion and seed-corn flies, Hylemya antiqua and H. platura (Diptera: Anthomyiidae) on an artificial diet with antibiotics. Appl. Entomol. Zool. 18: 62-69.

IshiKawa Y., Yamashita T. \& Nomura M. 2000: Characteristics of summer diapause in the onion maggot, Delia antiqua (Diptera: Anthomyiidae). J. Insect Physiol. 46: 161-167.

KaYUKAWA T. \& IshIKAWA Y. 2005: Detection of chill injuries in the pupae of the onion maggot, Delia antiqua (Diptera: Anthomyiidae). Appl. Entomol. Zool. 40: 193-198.

Kayukawa T., Chen B., Miyazaki S., Itoyama K., Shinoda T. \& IsHIKAWA Y. 2005: Expression of mRNA for the t-complex polypeptide-1, a subunit of chaperonin CCT, is upregulated in association with increased cold hardiness in Delia antiqua. Cell Stress Chaper. 10: 204-210.

KošŤÁL V. \& ŠIMEK P. 1995: Dynamics of cold hardiness, supercooling and cryoprotectants in diapausing and non-diapausing pupae of the cabbage root fly, Delia radicum. J. Insect Physiol. 41: 627-634.

LeE R.E. JR \& DeNLINGER D.L. (eds) 1991: Insects at Low Temperature. Chapman and Hall, New York, 513 pp.

Nomura M. 2000: Studies on Completion of Winter and Summer Diapause in the Onion Maggot, Delia antiqua. Doctoral thesis, University of Tokyo.

Nomura M. \& IshiKawa Y. 2001: Dynamic changes in cold hardiness, high temperature tolerance and trehalose content in the onion maggot, Delia antiqua (Diptera: Anthomyiidae), associated with the summer and winter diapause. Appl. Entomol. Zool. 36: 443-449.

Received October 25, 2005; revised and accepted March 6, 2006 